\title{
Study of Dermatoglyphics In Thalassemia Major in Vidharbha Region by Quantitative Analysis of Finger Print
}

\author{
Dr Yogesh Shridhar Ganorkar $\mathrm{Md}^{1}$,Dr Sugat Kawale $\mathrm{Md}^{2}$, \\ Dr S.V. Pandit $\mathrm{Ms}^{2}$,Dr Rakeshkumar Jha ${ }^{3}$ \\ Shri Vasantrao Naik Govt Medical College, Yavatmal (MS)
}

\begin{abstract}
Introduction: Dermatoglyphics is scientific study of epidermal ridges and their configuration on the volar aspect offinger, palm, toes and sole. Several variation may found in the patient with thalassemia major.

Aims: This study aimed to diagnose the thalassemia patient by using dermatoglyphic pattern.

Material and method: The above study was carried out in deptt. Of anatomy,svngmc yavatmal and comprised of dermatoglyphic pattern of 100 patients along with 100 normal individual to serve as control against thalassemic patients. Dermatoglyphics prints was taken by ink method and studied by quantitative analysis.

Result: Out of 100 cases, there is increase in the mean value of AFRC( Absolute finger ridge count)in thalassemia male and female. Total finger ridge counting shows significance increase in mean value of TFRC (Total finger ridge count).

Conclusion: There is significance difference in mean value of AFRC and TFRC in thalassemic patient when compared with control.
\end{abstract}

Keyword :Thalassemia major, Dermatoglyphics,Ridge,Control,ink method.

\section{Introduction}

Dermatoglyphics, is a scientific study of epidermal ridges and their configuration on the volar aspect of fingers, palm, toes and sole. The word has its origin from Greek word "Derma" meaning skin and "Glyphics" meaning carved.Initially, this term signified study of ridges, flexion creases. Other secondary folds were included in it latter. So Dermatoglyphics, as it stands today, means study of ridges, secondary folds, flexion creases of hand,sole,finger and toes.

In the past, Dermatoglyphics has no importance beyond their use in personal indentification.However with the growing interest in this sphere among anatomist, physical anthropologist and genetists and their invaluable contribution, laid the foundation to the development of this field.

The ridge pattern depend upon cornified layer of epidermis as well as dermal papillae. The characteristic pattern of epidermal ridges are determined since their formation in foetus as there is proliferation of cell in epidermis which is invaded and moulded by dermal papillae.The original ridge characteristics are not disturbed unless the tissues, deep to this zone is destroyed by any wound or disease process.

The term thalassemia is derived from a Greek word that means 'the sea' (Mediterranean) in the blood.(Weatherall D.S.) ${ }^{1}$."Thalassemia" . a heterogeneous group of hereditary hemolytic anemias which have in common a decreased rate of synthesis of one or more hemoglobin polypeptide chains and are classified according to the chain involved ie. $\alpha, \beta, \delta$. The two major categories are $\alpha$ (alpha) and $\beta$ (beta) thalassemia. It is manifested in homozygotes by profound anemia or death in utero and in heterozygotes by relatively mild red cell anomalies. $\square-$ thalassemia, that caused by diminished synthesis of beta chains of hemoglobin. The homozygous form (Cooley's anemia); Mediterranean anemia; erythroblastic anemia of childhood; (thalassemia major) in which hemoglobin A is completely absent. Which appears in the newborn period as severe form marked by a hemolytic hypochromic microcytic anemia, pronounced hepatosplenomegaly skeletal deformation, mongoloid facies and cardiac enlargement. The heterozygous form (thalassemia minor), in which hemoglobin A synthesis usually is retarded.Patient is asymptomatic but there is sometimes moderate anemia and splenomegaly.

Thus the thalassemia includes four clinical syndromes of increasing severity. These are :

i) Silent carrier

ii) Thalassemia trait

iii) Thalassemia intermedia and

iv) Thalassemia major.

Thalassemia major also known as Cooley's anemia or homozygous $\beta$ thalassemia, is a clinically severe disorder due to inheritance of two $\beta$ thalassemia alleles, one on each copy of chromosome no. 11. As a consequence of diminished $\mathrm{HbA}$ synthesis, the circulating red cells are small, thin and distorted, they contain 
markedly reduced amount of hemoglobin. Accumulation of free $\alpha$ globin chain leads to the deposition of precipitated of these chains to the determinant of the erythrocytes and its precursor cells in the bone marrow.

Cooley's anaemia is the most severe from of congenital haemolytic anemia. Hypochromic anemia of thalassemia major is so severe that chronic blood transfusion is usually required. The patients have very short life, death usually occurs by ten years of age .(Ghai O.P.1987) ${ }^{2}$

The mainstay of the management of severe $\beta$ thalassemia remains of necessary blood transfusion .(Fosburg M.T.1990)

\section{Aims and Objectives}

Thalassemia infact is a hemoglobinopathy that is seen in early first three decades of life is well determined by various factors like age, sex and caste. That is why the present study is undertaken with the aim of studying dermatoglyphics and dermatoglyphic patterns in thalassemic patients.

Thus the aims of this study are as follows -

1. To study the dermatoglyphic patterns in thalassemic patients and to compare the same with similar studies done by other workers of the world.

2. To compare the dermatoglyphics in thalassemic patients with normal population

\section{Material and Method}

The present study was carried out in the Department of Anatomy, shri Vasantrao naik government medical college Yavatmal from the year 2012 to 2014 and comprised of dermatoglyphic patterns of 100 subjects (60 males and 40 females) were taken from Department of Pediatrics,shri Vasantrao naik Government Medical College and Hospital, yavatmal. Department.

Majority of the study population belongs to the Outpatient Departments and Wards of Pediatric

Diagnostic assessments of patients were based on clinical histories, medical records and family history data. The palmar prints of 100 normal individuals (60 males and 40 females) were collected to serve as a control against the thalassemic patients. All those persons were found normal on physical examination and are considered as healthy.

\section{Method Of Dermatoglyphic Printing -} and $\operatorname{Midlo}(1961)^{4}$

Dermatoglyphic prints were taken by the 'Ink Method' as described by Cummins(1936) and Cummins Quantitative analysis of finger prints.

i) Total finger ridge count ( TFRC)

ii) Absolute finger ridge count (AFRC)

\section{Morphology}

Dermatoglyphic Configurations -

Ridge detail (Minutae)

Intricate details of structure of epidermal ridges are termed as minutiae by Galton (1892) $)^{5}$. They are highly variable but unique to an individual. They are valuable and reliable for personal identification. They do not have other medical value.

Quantitative Analysis

Many Dermatoglyphic characteristics can be described quantitatively.

\section{Ridge Counting}

Ridge counting indicates the pattern size. It is primarily utilized on finger tips as a way of expressing the distance between digital triradii to the ridge density in a given area.

\section{Finger Ridge Counting}

Counting is along a straight line connecting the triradial point to the point of core. Ridges containing triradial point and point of core are excluded. In case of whorl with two triradii and at least one point of core, two different counts are made, one from each triradii. Each count is made along a line drawn between the triadial point and the nearer point of core. The two counts are specified as first radial and second ulnar counts.

Usually the symbols and ridge counts are recorded in order, beginning with the little finger of the left hand continuing to the thumb, while digits of right hand are started with thumb and continued up to little finger. Because the ridge counts are used to express the size, only the largest count is scored in a pattern with more than one possible count. Both simple and tented arches have ' 0 ' count. 
To some extent, ridge count reflects the pattern type (Holt 1961) .

Total Finger Ridge Count (TFRC)

TFRC represents the sum of ridge counts of all ten digits, where only larger count is used on those digits with more than one ridge count. It express size of pattern.

Absolute Finger Ridge Count (AFRC)

AFRC is the sum of the ridge counts from all the separate triradii on fingers. It reflects the pattern size as well as pattern intensity, which depends the pattern type.

\section{Observations And Results}

The dermatoglyphic patterns are analyzed according to sex and bi-hand. They are subjected to nonparametric statistical tests to evaluate significant pattern of identifiable differences between the Thalassemics and Controls.

The handprint patterns are analyzed under the following headings :

Quantitative analysis of finger prints.

(a) Total Finger Ridge Count (TFRC).

(b) Absolute Finger Ridge Count (AFRC).

\section{Quantitative characteristics of finger dermatoglyphics -}

Holt (1961),stated that the ridge counts which are size related numerical representatives of pattern types are considered to be greatest significance in genetic terms.

Table no. 1 shows frequency distribution of Absolute finger ridge count (AFRC) among thalassemia and controls, which effectively summarize the quantitative characteristics of both hands.

Table No. 01

Frequency Distribution Of Absolute Finger Ridger Count (Afrc) Among Thalassemis And Controls.

\begin{tabular}{|c|c|c|c|c|c|c|c|c|c|c|c|c|}
\hline \multirow{3}{*}{$\begin{array}{l}\text { CLASS } \\
\text { INTERVAL } \\
\text { OF AFRC }\end{array}$} & \multicolumn{6}{|c|}{ THALASSEMIA } & \multicolumn{6}{|c|}{ CONTROLS } \\
\hline & \multicolumn{2}{|c|}{ M } & \multicolumn{2}{|l|}{$\mathbf{F}$} & \multicolumn{2}{|c|}{$\mathbf{M}+\mathbf{F}$} & \multicolumn{2}{|c|}{$\mathbf{M}$} & \multicolumn{2}{|l|}{$\mathbf{F}$} & \multicolumn{2}{|c|}{$\mathbf{M}+\mathbf{F}$} \\
\hline & NO & $\%$ & NO & $\%$ & NO & $\%$ & NO & $\%$ & NO & $\%$ & NO & $\%$ \\
\hline $0-25$ & 00 & 0.00 & 00 & 0.00 & 00 & 0.00 & 01 & 1.66 & 01 & 2.50 & 02 & 2.00 \\
\hline $26-50$ & 00 & 0.00 & 00 & 0.00 & 00 & 0.00 & 05 & 8.33 & 02 & 5.00 & 07 & 7.00 \\
\hline $51-75$ & 01 & 1.66 & 00 & 0.00 & 01 & 1.00 & 05 & 8.33 & 02 & 5.00 & 07 & 7.00 \\
\hline $76-100$ & 01 & 1.66 & 01 & 2.50 & 02 & 2.00 & 13 & 21.66 & 05 & 12.50 & 14 & 14.00 \\
\hline $101-125$ & 05 & 8.33 & 06 & 15.0 & 18 & 18.00 & 17 & 28.33 & 12 & 30.00 & 19 & 19.00 \\
\hline $126-150$ & 10 & 16.66 & 09 & 22.50 & 27 & 27.00 & 04 & 6.66 & 10 & 25.00 & 16 & 16.00 \\
\hline $151-175$ & 24 & 40.00 & 09 & 22.50 & 18 & 18.00 & 03 & 5.00 & 03 & 7.50 & 08 & 8.00 \\
\hline $176-200$ & 13 & 21.66 & 06 & 15.00 & 19 & 19.00 & 06 & 10.00 & 02 & 5.50 & 08 & 8.00 \\
\hline $201-225$ & 05 & 8.33 & 08 & 20.00 & 13 & 13.00 & 04 & 6.66 & 03 & 7.50 & 11 & 11.00 \\
\hline $226-250$ & 01 & 1.66 & 01 & 2.50 & 02 & 2.00 & 02 & 3.33 & 00 & 0.00 & 08 & 8.00 \\
\hline
\end{tabular}

Table no. 2 shows statistical calculations for absolute finger ridge count. The table shows that there is increase in the mean values of AFRC in thalassemic males and females and also in thalassemic male and female combined series when compared with the controls.

Table No. 02

Statistical Calculations For Afrc.

\begin{tabular}{|l|l|l|l|l|l|}
\hline SUBJECT & SEX & X & S. D. & S.E. OF X & C.V. (\%) \\
\hline \multirow{4}{*}{ THALASSEMIA } & $\mathrm{M}$ & 163.59 & 30.75186 & 3.97311 & 18.79928 \\
\cline { 2 - 6 } & $\mathrm{F}$ & 163.13 & 35.67901 & 5064542 & 21.87286 \\
\cline { 2 - 6 } & $\mathrm{M}+\mathrm{F}$ & 163.36 & 33.21501 & 3.32151 & 20.33364 \\
\hline \multirow{3}{*}{ CONTROLS } & $\mathrm{M}$ & 117.36 & 53.38284 & 6.89701 & 45.49027 \\
\cline { 2 - 6 } & $\mathrm{F}$ & 136.83 & 51.34002 & 8.12342 & 37.52376 \\
\cline { 2 - 6 } & $\mathrm{M}+\mathrm{F}$ & 127.09 & 52.36102 & 5.23611 & 41.20318 \\
\hline
\end{tabular}



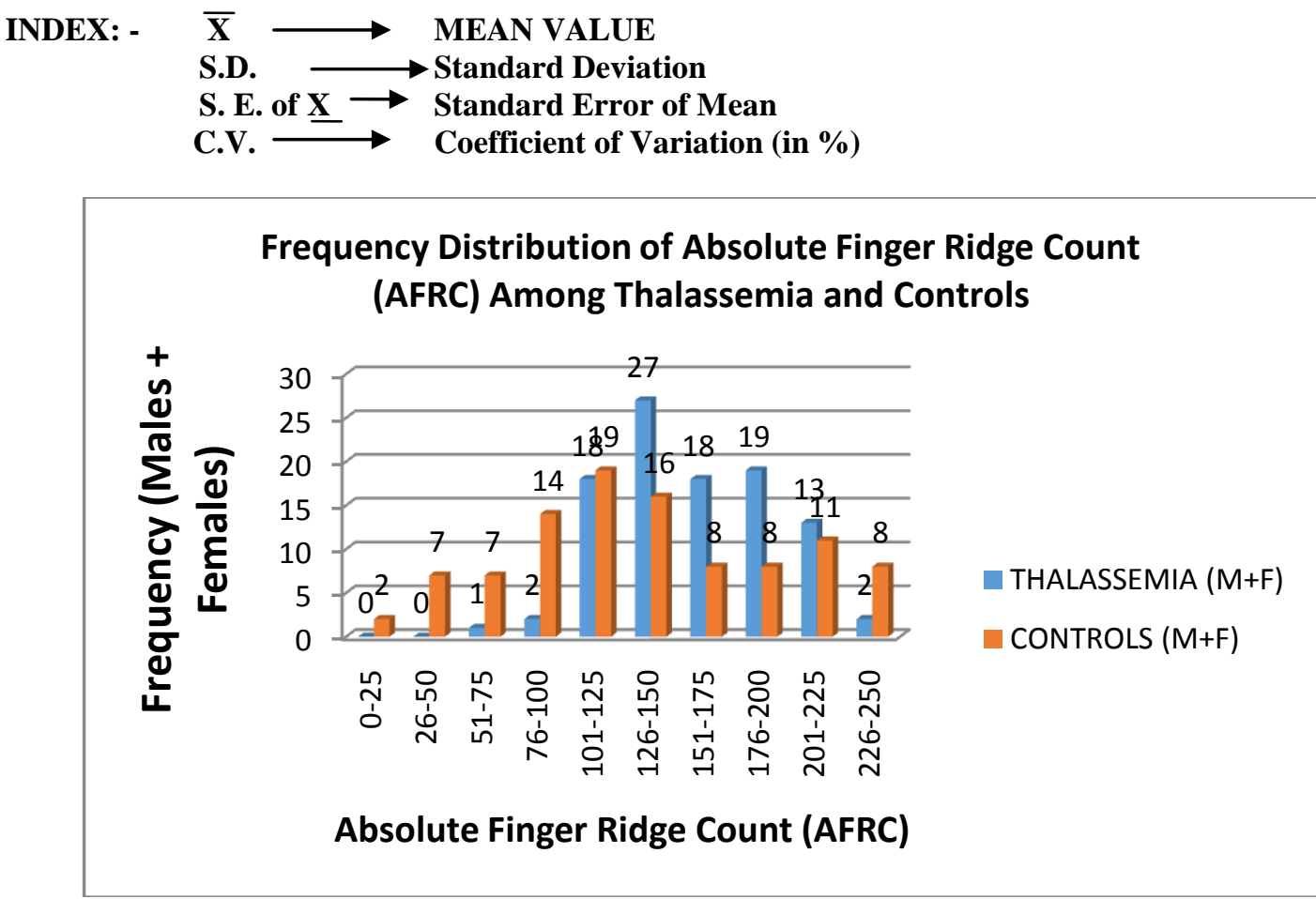

Table no. 3 shows frequency distribution of Total finger ridge count (TFRC) among thalassemia and controls.

Table No 03

Frequency Distribution Of Total Finger Ridge Count (Tfrc) Among Thalassemia And Controls.

\begin{tabular}{|c|c|c|c|c|c|c|c|c|c|c|c|c|}
\hline \multirow{3}{*}{$\begin{array}{l}\text { CLASS } \\
\text { INTERVAL } \\
\text { OF AFRC }\end{array}$} & \multicolumn{6}{|c|}{ THALASSEMIA } & \multicolumn{6}{|c|}{ CONTROLS } \\
\hline & \multicolumn{2}{|c|}{$\mathbf{M}$} & \multicolumn{2}{|l|}{$\mathbf{F}$} & \multicolumn{2}{|c|}{$\mathbf{M}+\mathbf{F}$} & \multicolumn{2}{|c|}{$\mathbf{M}$} & \multicolumn{2}{|l|}{$\mathbf{F}$} & \multicolumn{2}{|c|}{$\mathbf{M}+\mathbf{F}$} \\
\hline & NO & $\%$ & NO & $\%$ & NO & $\%$ & NO & $\%$ & NO & $\%$ & NO & $\%$ \\
\hline $0-25$ & 00 & 0.00 & 00 & 0.00 & 00 & 0.00 & 01 & 1.66 & 01 & 2.50 & 03 & 3.00 \\
\hline $26-50$ & 00 & 0.00 & 00 & 0.00 & 00 & 0.00 & 03 & 5.00 & 01 & 2.50 & 04 & 4.00 \\
\hline $51-75$ & 01 & 1.66 & 01 & 2.50 & 02 & 2.00 & 12 & 20.00 & 01 & 2.50 & 07 & 7.00 \\
\hline $76-100$ & 10 & 16.66 & 01 & 2.50 & 21 & 21.00 & 16 & 26.66 & 13 & 32.50 & 23 & $\begin{array}{l}23.0 \\
0\end{array}$ \\
\hline $101-125$ & 08 & 13.33 & 14 & $\begin{array}{l}30.5 \\
0\end{array}$ & 52 & 52.00 & 13 & 21.66 & 14 & 35.00 & 28 & $\begin{array}{l}28.0 \\
0\end{array}$ \\
\hline $126-150$ & 10 & 16.66 & 12 & $\begin{array}{l}30.0 \\
0\end{array}$ & 20 & 20.00 & 03 & 10.00 & 05 & 2.50 & 12 & $\begin{array}{l}12.0 \\
0\end{array}$ \\
\hline $151-175$ & 30 & 50.00 & 11 & $\begin{array}{l}27.5 \\
0\end{array}$ & 03 & 3.00 & 04 & 6.66 & 02 & 5.00 & 08 & 8.00 \\
\hline $176-200$ & 00 & 0.00 & 01 & 2.50 & 01 & 1.00 & 02 & 3.33 & 02 & 5.00 & 05 & 5.00 \\
\hline $201-225$ & 01 & 1.66 & 00 & 0.00 & 01 & 1.00 & 02 & 3.33 & 01 & 2.50 & 08 & 8.00 \\
\hline $226-250$ & 00 & 0.00 & 00 & 0.00 & 00 & 0.00 & 01 & 1.66 & 00 & 0.00 & 02 & 2.00 \\
\hline
\end{tabular}

Table no. 4 shows statistical calculations for total finger ridge count. The table shows significant increase in the mean values of TFRC in thalassemic males and females and also in thalassemic male and female combined series when compared with the controls.

Table No. : - 04

Title: - Statistical Calculation For Tfrc.

\begin{tabular}{|c|l|l|l|l|l|}
\hline SUBJECT & SEX & $\mathrm{X}$ & S.D. & S.E. O F X & C.V. (\%) \\
\hline \multirow{3}{*}{ THALASSEMIA } & $\mathrm{M}$ & $\mathbf{1 4 0 . 3 7}$ & $\mathbf{3 0 . 2 4 7 2 0}$ & $\mathbf{3 . 9 0 7 9 1}$ & $\mathbf{2 1 . 5 4 9 7 0}$ \\
\cline { 2 - 6 } & $\mathrm{F}$ & $\mathbf{1 3 5 . 1 1}$ & $\mathbf{2 5 . 0 0 7 7 0}$ & $\mathbf{3 . 9 5 6 9 3}$ & $\mathbf{1 8 . 5 1 0 5 8}$ \\
\cline { 2 - 6 } & $\mathrm{M}+\mathrm{F}$ & $\mathbf{1 3 7 . 7 4}$ & $\mathbf{2 7 . 6 2 7 5 5}$ & $\mathbf{2 . 7 6 2 7 3}$ & $\mathbf{2 0 . 0 5 9 2 1}$ \\
\hline \multirow{3}{*}{ CONTROLS } & $\mathrm{M}$ & $\mathbf{1 0 3 . 6 1}$ & $\mathbf{4 6 . 6 6 8 7 7}$ & $\mathbf{6 . 0 2 9 5 6}$ & $\mathbf{4 5 . 0 4 7 0 7}$ \\
\cline { 2 - 6 } & $\mathrm{F}$ & $\mathbf{1 1 5 . 8 3}$ & $\mathbf{3 8 . 1 7 9 1 1}$ & $\mathbf{6 . 0 4 0 9 0}$ & $\mathbf{3 2 . 9 6 4 1 7}$ \\
\cline { 2 - 6 } & $\mathrm{M}+\mathrm{F}$ & $\mathbf{1 0 9 . 7 2}$ & $\mathbf{4 2 . 4 2 3 9 4}$ & $\mathbf{4 . 2 4 2 3 0}$ & $\mathbf{3 8 . 6 6 9 1 6}$ \\
\hline
\end{tabular}

INDEX: $-\overline{\mathbf{X}} \longrightarrow$ MEAN VALUE
S.D.
Standard Deviation 


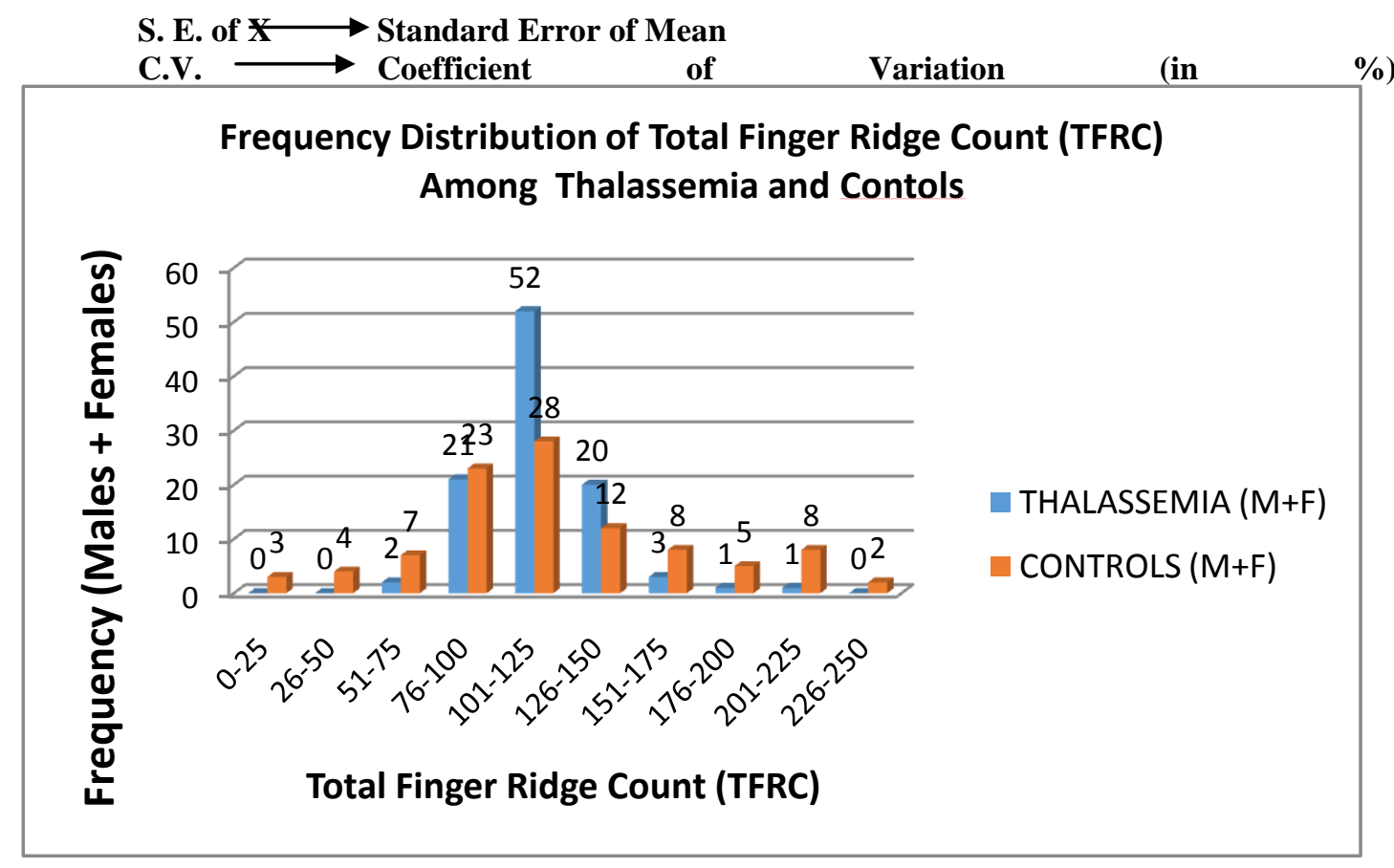

From above it is observed that there are significant differences in the mean values of AFRC and TFRC in thalassemics when compared with the controls.

\section{Discussion}

Dermatoglyphics is used as diagnostic aid in number of diseases which have strong hereditary basis.Thalassemia is a genetic defect having at least 91 point mutations and several deletional mutations which were identified within and around the beta globin chain gene all affecting the expression of the beta globin chain gene resulting in defects in activation, initiation, transcription and/or termination from this certain dermatoglyphic variations are to be expected in this disease. Thus dermatoglyphic patterns should help on expression of genes in thalassemia

This study includes 100 patients (60 males and 40 females) of thalassemia and 100 healthy controls (60 males and 40 females) of same age group. The prints were obtained by Ink method and analyzed to detect variations in dermatoglyphic features among thalassemic and controls. The samples have been taken from both heterozygous and homozygous states

The parameters observed among thalassemics and controls were

ii) Quantitative analysis of finger prints i.e. Total and Absolute finger ridge count.

In the present study, observations were first subjected to non parametric tests of statistical significance and then compared with the findings of similar studies done by previous workers.

The findings of this study are processed, compared and discussed under the following headings.

II. Total Finger Ridge Count (TFRC) and Absolute Finger Ridge Count (AFRC) -

In this study, TFRC is significantly increased in thalassemic males and females and a significant difference is found in the count when thalassemic males and females combined series is compared with those of controls. AFRC is also significantly increased in both male and female thalassemics, and male and female combined series than those of controls. Thus differences observed in TFRC and AFRC are found to be statistically significant.

The above findings coincide with the findings obtained by Rosener F. and Spriggs H. A. (1968-69) ${ }^{7}$, that the mean total ridge count was significantly increased in thalassemics. Saha K. C; Chatterjea J. B. and Mukherjee D. P. $(1971)^{8}$, stated that higher values of total ridge count were seen in males. But they found lower values in female thalassemics that was so because of different methods of calculations and classifications 9 .

\section{Conclusions}

The study of epidermal ridge patterns of palms and soles is known as dermatoglyphics. It is recognized since long as a valuable method for anthropological, medicolegal studies. Now a day it is useful in cytogenetics. Dermatoglyphic patterns are determined by genetic factors and it has been proved that 'beta globin chain' gene is responsible for thalassemia and chromosome \# 11p15.5 is seen in thalassemia. So there is a great scope for the 
study of relationship between thalassemia and dermatoglyphics.

This study attempts to analyse whether any specific pattern, exist for thalassemia and whether that serve as an early diagnostic tool. This study was carried out over a period of two years and comprises 200 subjects (100 thalassemia and 100 controls).For dermatoglyphic analysis, permanent palmar and finger print records were taken by ink method described by Cummins and Midlo (1961). The prints were analysed and tested for statistical significance between thalassemics and control groups.TFRC and AFRC both are significantly increased in male and female thalassemics than controls. These observations are compared and correlated with those of the previous workers and an attempt has been made to find out whether there is a significant correlation between thalassemic dermatoglyphics and other factors like regional, sexual, caste and digital variations.

From this study, the following significant conclusions are drawn -

1) There is definitely a statistically significant difference in the dermatoglyphic patterns in thalassemic patients as compared with normal general population.

2) There is no regional variation seen amongst dermatoglyphic patterns in subjects of different region.

3) Caste preponderance is seen in Sindhis, Punjabis, Cuttchis, Khatris and Scheduled castes, who were commonly affected by thalassemia.

4) There is a statistically significant difference in dermatoglyphic patterns of male and female subjects affected by thalassemia.

5) There is a statistically significant variation in dermatoglyphic patterns of different digits of the same individual affected by thalassemia.

\section{References}

[1]. Weatherall D. J.; Clegg J. B.; Blanksen J. A.; Mustafa D.; BoiDoky F. S. and Chaudhary D. S. (1971)

[2]. Preliminary survey's for the prevalence of thalassemia genes in some African populations. Ann. Trop. Med. Parasit, $65 ; 253$ - 265. Ghai O. P. (2013),

[3]. Cooley's anemia; Issue Jan 2008

[4]. Fosburg M. T. and Nathan D. G. (1990),

[5]. Treatment of Cooley's anemia, Blood, 76; 435. )

[6]. Cummins and Midlo (1926)

[7]. Palmar and plantar epidermal ridge configurations in Europeon. American Jou. Phy. Anthropology, 9; 471 - 502. Galton F. (1892),

[8]. Finger prints London Mc Millon. Quoted by Cummins and Midlo (1961). Holt S. B. and Lindstein (1964),

[9]. Dermatoglyphic anomalies in Turner's syndrome. Ann. Hum. Genet. London, 28; 87- 100 .

[10]. Rosner F. and Spriggs H. A. (1968)

[11]. American journal Med. Sci., 254; 695.

[12]. Dermatoglyphic studies in patients with Cooley's anemia. Ann. N. Y. Acad. Sci. 165(1); 378-386.

[13]. Saha K. C; Mukherjee J. B. and Chatterjee D. P. (1973),

[14]. Derrmatoglyphics in thalassemia syndrome. Jou. IMA, 61(5); 205 - 211.

[15]. Kumar S.; Kumar N. and Mittra M. K. (1971),

[16]. Evolution of dermatoglyphics in thalassemia. Jou. API Nov. 19(11); 819-821.

[17]. ICMR task force study (1993),

[18]. Indian population and prevalence of carriers of beta thalassemia,37-38. 